\title{
Increased circulating rather than spinal cytokines accompany chronic pain behaviors in experimental bone cancer and arthritis
}

\author{
Line Pourtau ${ }^{1,2}$, Amarins Nieske Heeringa ${ }^{1,2}$, Carole Rovère ${ }^{3,4}$, Agnès Aubert ${ }^{1,2}$, Jean-Louis Nahon ${ }^{3,4}$, \\ Sylvain Miraux ${ }^{5,6}$, Jan Pieter Konsman ${ }^{1,2}$ \\ ${ }^{1}$ CNRS, PsychoNeuroImmunologie, Nutrition et Génétique, UMR 5226, 33076 Bordeaux, France \\ ${ }^{2}$ Univ. Bordeaux, PsyNuGen, UMR 5226, 33076 Bordeaux, France \\ ${ }^{3}$ CNRS, Institut de Pharmacologie Moléculaire et Cellulaire, UMR 7275, 06560 Valbonne, France \\ ${ }^{4}$ Univ. Nice Sophia Antipolis, 06130 Nice, France \\ ${ }^{5}$ CNRS, Résonance Magnétique des Systèmes Biologiques, UMR 5536, 33076 Bordeaux, France \\ ${ }^{6}$ Univ. Bordeaux, RMSB, UMR 5536, 33076 Bordeaux, France
}

A B S T R A C T

\begin{abstract}
Aim: Peripheral cytokines contribute to arthritis and bone cancer pain through sensory nerve actions. However, increased spinal cytokine and glial filament expression, coined neuroinflammation, has also been proposed to play a part in chronic pain. Therefore, spinal cord, dorsal root ganglia and circulating cytokines were compared in murine arthritis and bone cancer models in relationship to behavioral signs of pain. Methods: Exploratory behaviors were studied after intra-articular complete Freund's adjuvant or bone intramedullary sarcoma cell injection. Nervous tissue and blood cytokine expression were determined by real-time polymerase chain reaction (PCR) and multiplex immunoassays, respectively. Results: PCR analysis did not reveal any hallmark of spinal neuroinflammation in spontaneously-behaving mice with cartilage or bone lesions. However, imposed paw stimulation during joint inflammation increased spinal interleukin-1 $\beta$ (IL-1 $\beta$ ) expression. Spontaneous paw guarding during rearing was displayed by animals with joint inflammation and bone destruction and was accompanied by increased circulating IL- 6 and monocyte chemoattractant protein-1, respectively. In addition, dorsal root ganglia were found to constitutively express receptors for this chemotactic cytokine. Conclusion: Our findings indicate that spinal neuroinflammation is not a necessary condition for chronic pain and suggest that circulating cytokine action in dorsal root ganglia may contribute to experimental joint inflammation and bone cancer pain.
\end{abstract}

Key words: Arthritis, bone cancer, CCL2, cytokines, dorsal root ganglia, pain, spinal cord

\section{INTRODUCTION}

Painful joint inflammation affects millions of people with osteoarthritis and rheumatoid arthritis, whereas bone pain occurs in hundreds of thousands of patients with metastasized cancer. ${ }^{[1-3]}$ Arthritic and bone cancer pain are worsened by movement and thus reduce autonomy, ${ }^{[2,4-6]}$ for instance by interfering with the capacity to prepare daily meals.

Local cytokine production is important in arthritis and bone cancer, but increased spinal cytokine and

\begin{tabular}{|l|l|}
\hline \multicolumn{3}{|c|}{ Access this article online } \\
\hline Quick Response Code: & \\
\hline & Website: \\
\hline & Www.nnjournal.net \\
\cline { 2 - 3 } & \\
\hline
\end{tabular}

glial filament expression, coined neuroinflammation, may also contribute to pain. ${ }^{[7]}$ Indeed, both peripheral or intrathecal administration of the pro-inflammatory cytokines interleukin-1beta (IL-1 $\beta$ ) and tumor necrosis factor-alpha (TNF- $\alpha$ ) or of the chemotactic cytokine monocyte chemoattractant protein-1 (MCP-1/CCL2) increase experimental pain sensitivity. ${ }^{[8-14]}$ Moreover, peripheral and intrathecal cytokine antagonists attenuate hyperalgesia in inflammatory and bone cancer pain models. ${ }^{[8,15-21]}$ However, intrathecally-administered molecules readily spread to dorsal root ganglia (DRG), ${ }^{[22]}$ where receptor proteins for some cytokines are expressed, ${ }^{[23,24]}$ indicating that intrathecal cytokines or their antagonists may act centrally or peripherally.

Although some studies have reported increased spinal cytokine expression in experimental inflammatory and bone cancer pain, ${ }^{[19,25-28]}$ most studies have addressed spinal glial responses and found these to be variable..$^{[27-32]}$ 
Interestingly, paw palpation similar to pain sensitivity testing, and direct sensory nerve stimulation induce spinal transcription factor and IL- $1 \beta$ expression, respectively. ${ }^{[32-34]}$ In the present work, we therefore studied spinal and DRG expression as well as plasma concentrations of cytokines in murine models of arthritis and bone cancer in relationship to signs of spontaneous pain and paw palpation, rather than to pain sensitivity.

\section{METHODS}

\section{Animals}

One hundred $₫$ male $[$ C57/Bl6[P LFHCharlesRiver,Arbresle, France) weighing $25-30 \mathrm{~g}$ and $46 \mathrm{male} \mathrm{C} 3 \mathrm{H} / \mathrm{HeN}$ mice (Janvier Labs, Le Genest St-Isle, France) weighing 20-26 g were used. Four days before surgery, animals were housed individually in plastic transparent cages with unrestricted access to food and water in a room maintained at $21.5-22.5^{\circ} \mathrm{C}$. Lights were on from 3:00 a.m. to 15:00 p.m. All experimental procedures were approved by the local ethical committee (No. AP/2/11/2006).

\section{Arthritis and bone cancer induction}

C57/Bl6 mice were anesthetized with isoflurane and placed in a supine position to insert a 26-gauge needle into the knee joint as described by Gauldie et al ${ }^{[35]}$ Fifty $\mu \mathrm{L}$ of complete Freund adjuvant (CFA; Sigma-Aldrich, St. Louis, MO, USA) or mineral oil vehicle were injected on days 0 and 6 into the same joint [Figure 1]. $\mathrm{C} 3 \mathrm{H} / \mathrm{HeN}$ mice were anesthetized with isoflurane and injected with $10 \mu \mathrm{L}$ of phosphate buffer saline (PBS) containing $10^{5}$ NCTC-2472 cells (LGC Promochem, Molsheim, France) propagated in vitro or $10 \mu \mathrm{L}$ of PBS into the intramedullary canal of the femur in accordance with a previous report by Schwei et al. ${ }^{[33]}$

Behavioral testing

Reduced food intake and exploration are signs of pain in rodents. ${ }^{[36]}$ After surgery, food pellets and



Figure 1: Timelines representing joint inflammation (a) and bone cancer (b) experiments. CFA: complete freund adjuvant; MRI: magnetic resonance imaging body weight were measured every day. To assess exploratory activity during the dark phase, animals were placed in a dimly-lit (10 Lux) open field device $(40 \mathrm{~cm} \times 40 \mathrm{~cm})$ divided into 16 equal zones. Number of entries of the animal into a different zone and rearing with or without leaning against the wall were scored during $10 \mathrm{~min} .{ }^{[37]}$ To study hind paw guarding during rearing, animals were introduced into an inverted glass beaker of $20 \mathrm{~cm}$ diameter for $4 \mathrm{~min}$ during the light phase. ${ }^{[38]}$

As hallmarks of spinal neuroinflammation are variable between studies, in particular among those using CFA, we tested if mechanical non-noxious stimulation is one of the underlying factors. Therefore, half of the animals underwent hind paw palpation every second for $2 \mathrm{~min}$ and were sacrificed $90 \mathrm{~min}$ later [Figure 1]. To avoid any effect of mechanical allodynia testing on spinal gene expression, hind paw responses to von Frey filaments (0.16-2.4 g) applied to the plantar surface were studied a few minutes before sacrifice.

\section{Articular inflammation and bone destruction}

To assess inflammation, extracellular fluid was detected in vivo using T2-weighted magnetic resonance imaging (MRI) on a $4.7 \mathrm{~T}$ horizontal magnet (Bruker, Ettlingen, Germany). To determine bone destruction, 3D FLASH-based magnetic resonance microscopy of femurs was carried out ex vivo on a $9.4 \mathrm{~T}$ vertical magnet (Bruker Biospec 47/50, Ettlingen, Germany).

\section{Tissue preparation}

Two days after the second intra-articular injection, that is 8 days after the first injection, or 21 days after femur injection [Figure 1], animals were deeply anesthetized with sodium pentobarbital to allow for intracardiac puncture. Animals were rinsed with PBS after which animals assigned to immunohistochemical analysis were perfused with $4 \%$ paraformaldehyde in $0.1 \mathrm{~mol} / \mathrm{L}$ PBS. L3-L5 spinal cords and DRGs of these animals were post-fixed for $4 \mathrm{~h}$, cryoprotected in 30\% sucrose, frozen on dry ice and stocked at $-80^{\circ} \mathrm{C}$. For animals allocated to polymerase chain reaction (PCR) experiments, L3-L5 spinal cords and DRGs were removed within 3 min after rinsing with PBS and then frozen at $-80^{\circ} \mathrm{C}$.

\section{Spinal Fos expression}

Immunohistochemical detection of c-Fos and FosB transcription factors in the spinal cord was performed using rabbit antisera (diluted 1:2000; Santa Cruz Biotechnology, Santa Cruz, CA, USA) as previously described. ${ }^{[39]}$

\section{Circulating cytokines}

Blood samples were collected in EDTA-coated vials, centrifuged for $15 \mathrm{~min}$ at $3000 \mathrm{~g}$ at $4^{\circ} \mathrm{C}$ and the plasmas 
were frozen at $-80{ }^{\circ} \mathrm{C}$. IL-1 $\beta$, IL-6, IL-12, MCP-1/CCL2, TNF- $\alpha$ and interferon-gamma (IFN- $\gamma$ ) were measured using a 6-plex kit (BIORAD, Hercules, CA, USA). When estimated values were below the detection limit, animals were excluded from the analysis.

Cytokine and cytokine receptor expression in the spinal cord and dorsal root ganglias expression

RNA was extracted with Trizol (Invitrogen, Carlsblad, CA, USA) and concentrations were measured using a Nanodrop (Thermo scientific, Waltham, MA, USA). Quality check was performed with a Bioanalyzer (Agilent Technologies, Santa Clara, CA, USA) before reverse transcription to cDNA. Primers were designed [Table 1] and the resulting amplicon was validated using melting curve analysis. Real-time SYBR green-based comparative PCR was performed (DyNamoTM SYBER Green qPCR Kit, Finnzymes Oy, Espoo, Finland). Animals were excluded from the analysis if melting curves did not show a single peak. Relative expression of mRNA expression of IL-1 $\beta$, IL-1 receptor type 1 (IL-1R1), TNF- $\alpha$, TNF receptor 1 and 2 (TNFR1 and 2), MCP-1/CCL2, cyclooxygenase-2 (COX-2), prostaglandin E synthase and glial fibrillary acidic protein (GFAP) to glyceraldehyde 3-phosphate dehydrogenase expression was calculated as described by Pfaffl et al. ${ }^{[40]}$

Although the constitutive expression of IL-6 receptor protein has convincingly been shown in DRG, ${ }^{[23,24]}$ this is not necessarily the case for other cytokine receptors. Tyramide-amplified (PerkinElmer, Waltham, MA, USA) immunohistochemical detection of mouse CCR2 (rabbit antiserum diluted 1:25000, Avia Systems Biology, San Diego, CA, USA) was used on free-floating $20 \mu \mathrm{m}$ DRG cryostat sections to study constitutive protein expression of the MCP-1/CCL2 receptor. Specificity of immunoreactivity was assessed in CCR2-C57/Bl6 knockout mice (Jackson Laboratory-JAX ${ }^{\circledR}$ Mice, Bar Harbor, USA). Double-labelling for transient receptor potential vanilloid 1 (TRPV1; guinea pig antiserum diluted 1:500; Neuromics, Edina, MN, USA) was performed to determine if CCR2 was present in nociceptors.

\section{Data representation and statistical analysis}

Data were expressed as mean \pm standard error of mean or in case of PCR experiments as mean \pm standard error. Weekly food intake, body weight changes and exploratory behaviors were analyzed with two-way repeated measures analysis of variances (ANOVAs). Mechanical allodynia and spinal Fos expression were analyzed with two-way ANOVAs. Plasma cytokine concentrations were analyzed using $t$-test. Nonparametric Mann-Whitney tests were performed when normality or equal variance test failed. Differences in spinal mRNA expression were analyzed with Pair-Wise fixed reallocation randomization tests. ${ }^{[40]}$ In all cases, $P<0.05$ was considered as a statistically significant difference.

\section{RESULTS}

Two C57/Bl6 mice died during the second anesthesia for intra-articular injection of CFA or mineral oil.

\section{Magnetic resonance imaging}

T2-weighted MRI indicated some stifle joint edema after mineral oil injection [Figure 2a], but revealed much more intense and widespread inflammatory edema after CFA administration [Figure 2b]. No signs of inflammation were observed in contralateral joints. FLASH-based MRI revealed intact bone and marrow after PBS injection into the femur intramedullary canal [Figure 2c], whereas NCTC tumor cell injection resulted in trabecular bone destruction and irregular bone surfaces [Figure 2d].

\section{Food intake and body weight}

Food intake $[Z=-2.520 ; P<0.012$; Figure 3a] and body weight gain $(Z=-2.588 ; P<0.010)$ were significantly reduced during the week after CFA injection as compared to mineral oil. Weekly food intake [ $Z=-2.588 ; P<0.010$; Figure 3a] and body weight changes $(Z=-3.076 ; P<0.003)$ were significantly reduced during the $3^{\text {rd }}$ week after tumor cell injection into the femur in comparison to PBS administration.

Table I: List of forward and reverse primers used in this study $\left(5^{\prime}-3^{\prime}\right)$

\section{Gene}

IL-1 $\beta$

IL-1R1

TNF-a

TNFR1

TNFR2

MCP-1

COX2

MPGES

GFAP

GAPGH

\section{Forward primer}

GAAGAAGAGCCCATCCTCTG CCAGAAGTCTGTGGGAGTGA GCCTCTTCTCATTCCTGCTT AAGAAATGTCCCAGGTGGAG CCAATTGGTCTGATTGTTGG AGGTGTCCCAAAGAAGCTGT AATCCTTGCTGTTCCAATCC TAGAATAGGGACGGGGTCTG TTTCTCAACCTCCAGATCC TCAAGAAGGTGGTGAAGCAG
Reverse primer TCATCTCGGAGCCTGTAGTG TACGTTTTTGGGATGACAGG TGGGAACTTCTCATCCCTTT TCTCACTCAGGTAGCGTTGG AGGAGGGCTTCTTTTTTCCTC ATGTCTGGACCCATTCCTTC AGAATCCAGTCCGGGTACAG AGCATCCCAAAAGGCTAAGA CCGCATCTCCACAGTCTTTA TGGGAGTTGCTGTTGAAGTC

IL-1ß: interleukin-1 beta; IL-1R1: interleukin-1 receptor type 1; TNF-a: tumor necrosis factor-alpha; TNFR1 and 2: tumor necrosis factor receptor 1 and 2 ; MCP-1: monocyte chemoattractant protein-1; COX2: cyclooxygenase-2; mPGES: microsomal prostaglandin E synthase; GFAP: glial fibrillary acidic protein; GAPGH: glyceraldehyde 3-phosphate dehydrogenase 


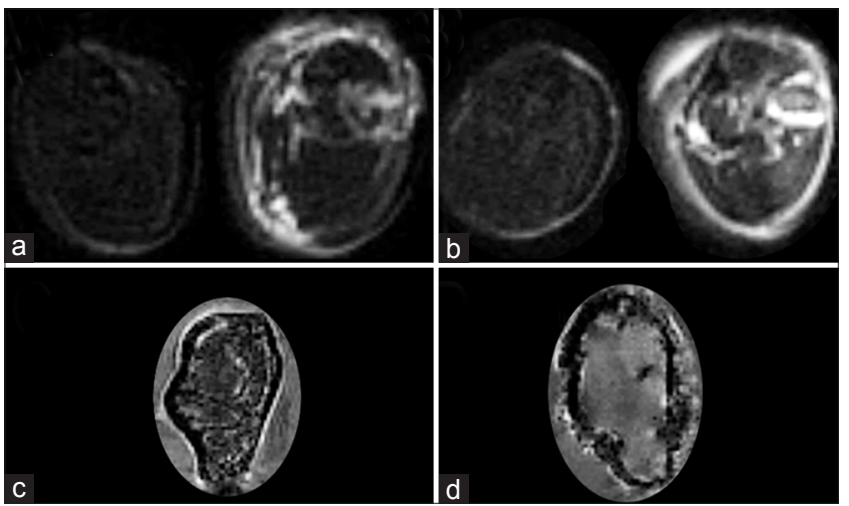

Figure 2: Joint inflammation and bone destruction. T2-weighted MRI indicating edema in contralateral (left) and ipsilateral (right) stifle joint one week after mineral oil (a) or CFA (b) injection. FLASH-based MRI of femurs after intramedullary injection of PBS (c) or NCTC cells (d) three weeks earlier. CFA: complete freund adjuvant; MRI: magnetic resonance imaging; PBS: phosphate buffer saline

\section{Exploratory behavior}

Dark phase exploratory activity in a dimly-lit open field device was significantly decreased on the $1^{\text {st }}$ day after intra-articular CFA injection as compared to that of mineral oil $[Z=-4.059 ; P<0.001$ and $Z=-3.553$; $P<0.004$; Figure 3b]. No differences in activity were observed 14, 17 or 20 days after tumor cell or PBS injection into the femur intramedullary [Figure 3b].

During the light phase, animals injected with CFA into their stifle joint reared less under the inverted beaker glass on days 2 and 5 compared to animals that received mineral oil $(Z=-4.860 ; P<0.001$ and $Z=-2.198 ; P<0.0280$, respectively). They also reared less against the wall compared with control animals on day $2(Z=-2.857 ; P<0.0043)$. While rearing against the wall, animals injected with CFA displayed significantly more hind paw guarding than those administered mineral oil on days $2(Z=5.411$; $P<0.001$ ) and $5[Z=-5.650 ; P<0.001$; Figure 3c $]$ after injection. No differences in rearing were observed after NCTC tumor cell or PBS injection into the femur intramedullary canal, but while rearing the former showed significantly more hind paw guarding than the latter on days $18(Z=2.457 ; P<0.015)$ and $21[Z=3.554 ; P<0.004$; Figure 3c] .

\section{Mechanical allodynia}

Mice injected intra-articularly with CFA required significant lower forces to elicit paw withdrawal compared with those administered mineral oil $[Z=-3.644 ; P<0.003$; Figure 3d]. Palpation of the hind paw had no effect on mechanical allodynia. Although bone tumor-bearing mice did not display active paw withdrawal, they allowed their paws to be lifted with the filament. This pressure-reducing behavior was significantly more frequent after femur NCTC tumor cell injection than after PBS administration $[Z=-2.124$; $P<0.034$; Figure 3d].
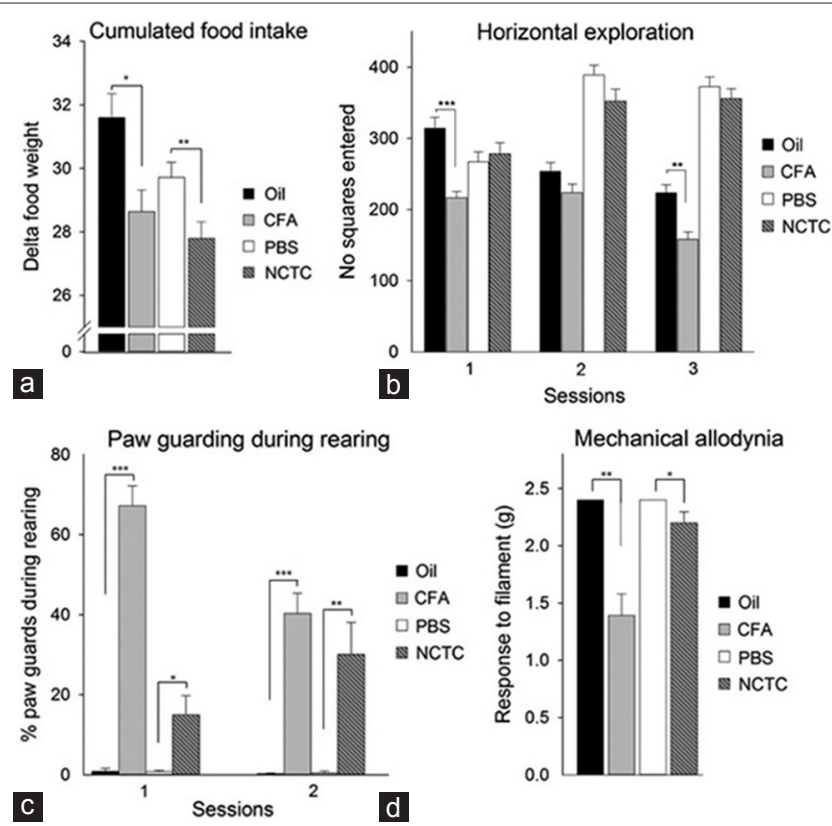

Figure 3: Behavioral effects of joint inflammation and bone cancer ( $n=18-23$, except for von Frey testing where $n=9-13$ ). a: food intake during last week of experiment. $\mathrm{b}$ : horizontal exploration of open field. Sessions 1,2 and 3 correspond to days 1, 4 and 7 after stifle joint injection and days 14, 17 and 20 after femur injection, respectively. c: percentage of paw guarding during rearing against wall. Sessions 1 and 2 correspond to days 2 and 5 after stifle joint injection and days 18 and 21 after femur injection, respectively. d: paw reaction to von Frey filament stimulation on the last day. Statistical differences: ${ }^{*} P<0.05$, ${ }^{* *} P<0.01$ and ${ }^{* \star *} P<0.001$. CFA: complete freund adjuvant; PBS: phosphate buffer saline

\section{Spinal Fos expression}

The number of c-Fos immunoreactive cells in L3-L5 spinal cord increased significantly after intra-articular CFA injection $(\mathrm{F}[1,27]=10.24 ; P<0.004)$ and after non-noxious hind paw palpation $(\mathrm{F}[1,27]=17.85$; $P<0.001$ ), whereas the number of FosB-immunoreactive cells did not differ. No differences in the numbers of c-Fos-and FosB-immunoreactive cells were found between NCTC-bone tumor-bearing and PBS-injected control animals.

\section{Plasma cytokine concentrations}

Significantly higher IL-6 concentrations in plasma were found in mice that received intra-articular CFA as compared to mineral oil $[Z=-2.237 ; P<0.019$; Figure 4] while significantly increased circulating MCP-1/CCL2 levels were observed in animals injected with NCTC tumor cells rather than with PBS into their femur $[Z=3.269 ; P<0.002$; Figure 4]. Circulating MCP-1/CCL2 was probably tumor-derived as NCTC bone tumors were highly MCP-1/CCL2-immunoreactive.

\section{Spinal and dorsal root ganglia mRNA expression}

L3-L5 spinal expression of COX-2 mRNA was significantly increased $(P<0.004)$ in animals that received intra-articular CFA compared with those receiving vehicle in the absence of paw palpation [Table 2]. Among animals that underwent paw palpation, CFA-injected mice showed significantly 
increased IL-1 $\beta(P<0.009)$, IL-1R1 $(P<0.002)$ and COX-2 $(P<0.003)$ mRNA expression compared with vehicle-treated animals [Table 2]. Spinal gene expression was not found to be different between femur injections, except for a decrease in TNFR1 expression in bone cancer-bearing mice compared to control animals $(P<0.011)$.

No changes in DRG mRNA expression were observed, except for a significant increase in COX-2 mRNA $(P<0.027)$ in animals that received intra-articular CFA compared to those administered vehicle in the absence of paw palpation [Table 2]. In animals that underwent paw palpation, this effect was absent.

\section{Dorsal root ganglia CCR2 protein expression}

Numerous CCR2-immunoreactive cells were observed in $\mathrm{C} 3 \mathrm{H} / \mathrm{HeN}$ DRGs, but their numbers were not

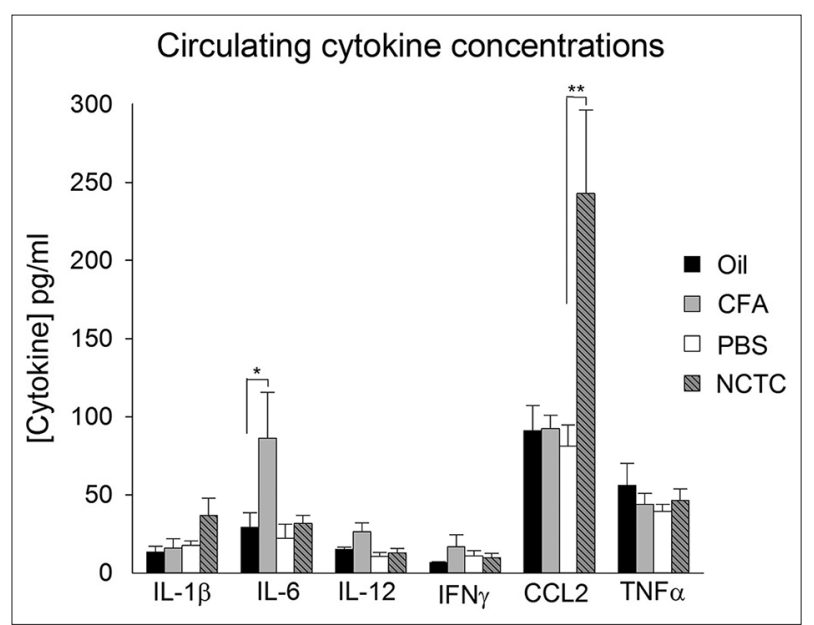

Figure 4: Plasma cytokines in joint inflammation and bone cancer $(n=9-11)$. Statistical differences: ${ }^{*} P<0.05$ and ${ }^{* \star} P<0.01$. CFA: complete freund adjuvant; PBS: phosphate buffer saline; IL: interleukin; IFN: interferon; TNF: tumor necrosis factor statistically different between femur injections. Similar findings were obtained in C57/Bl6 wild-type mice [Figure 5a]. The signal was specific since no labeling was observed in CCR2-C57/Bl6 knockout mice, except for some interstitial staining [Figure 5b]. DRG CCR2-immunoreactivity occurred in nociceptors as it was found to be present in TRPV1-positive cells both by epifluorescence [Figure 5c-h] and confocal microscopy [Figure 5i-k].

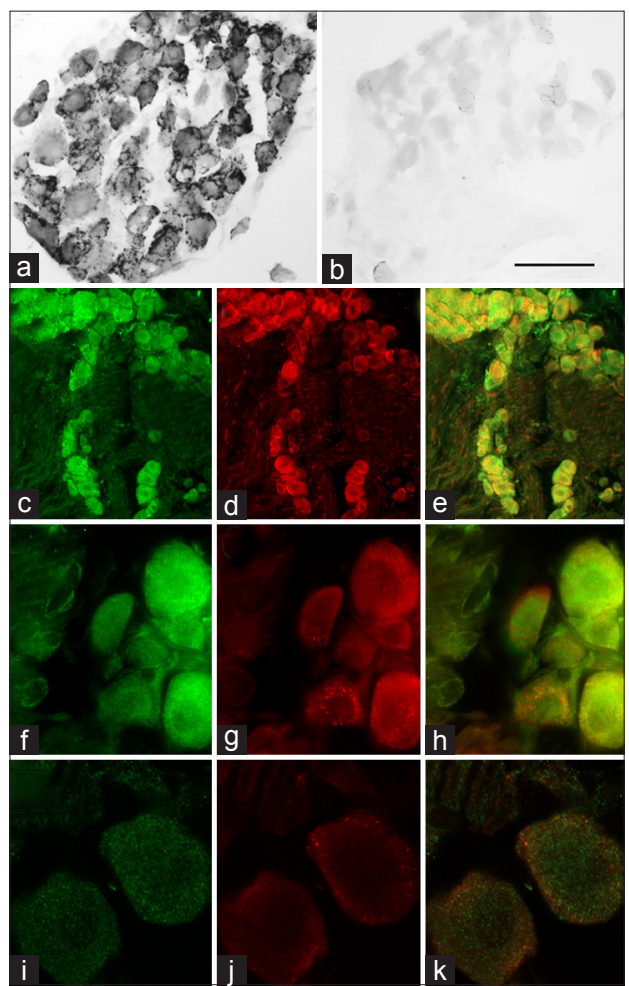

Figure 5: DRG CCR2-immunoreactivity. Presence of CCR2-immunoreactive DRG cells in wild-type (a) but not in CCR2 knockout (b) mice. CCR2 immunoreactivity (c; f; i) occurred largely in TRPV1-positive neurons $(\mathrm{d}, \mathrm{g}, \mathrm{j})$ as illustrated by merged images from epifluorescence $(e ; h)$ or confocal microscopy $(k)$. Scale bar indicates $100 \mu \mathrm{m}$ for a and b. DRG: dorsal root ganglia

\begin{tabular}{|c|c|c|c|c|c|}
\hline & CFA $\leftrightarrow$ oil & CFA $_{p} \leftrightarrow$ oil $_{p}$ & CFA $_{p} \leftrightarrow$ CFA & Oil $_{p} \leftrightarrow$ oil & NCTC $\leftrightarrow$ PBS \\
\hline \multicolumn{6}{|l|}{ Spinal cord } \\
\hline $\mathrm{IL}-1 \beta$ & $1.21 \pm 0.35$ & $1.80 \pm 0.43^{* \star}$ & $1.27 \pm 0.33$ & $0.85 \pm 0.23$ & $0.96 \pm 0.29$ \\
\hline IL-1R1 & $1.76 \pm 0.44$ & $2.68 \pm 0.55^{\star * *}$ & $1.50 \pm 0.36^{*}$ & $0.98 \pm 0.92$ & $0.90 \pm 0.23$ \\
\hline TNF-a & $1.78 \pm 0.54$ & $0.99 \pm 0.27$ & $0.98 \pm 0.33$ & $1.75 \pm 0.41$ & $0.91 \pm 0.23$ \\
\hline TNFR1 & $1.38 \pm 0.34$ & $1.54 \pm 0.45$ & $1.31 \pm 0.39$ & $1.17 \pm 0.28$ & $0.73 \pm 0.14^{\star *}$ \\
\hline TNFR2 & $0.90 \pm 0.29$ & $1.06 \pm 0.22$ & $1.15 \pm 0.33$ & $0.81 \pm 0.27$ & $0.73 \pm 0.24$ \\
\hline MCP-1 & $1.31 \pm 0.68$ & $0.98 \pm 0.23$ & $0.66 \pm 0.19$ & $0.90 \pm 0.44$ & $1.04 \pm 0.32$ \\
\hline cox2 & $3.43 \pm 1.19^{*}$ & $4.38 \pm 1.83^{\star \star}$ & $1.24 \pm 0.58$ & $1.00 \pm 0.26$ & $1.11 \pm 0.35$ \\
\hline mPGES & $0.79 \pm 0.25$ & $1.13 \pm 0.22$ & $1.56 \pm 0.29$ & $0.95 \pm 0.29$ & $0.86 \pm 0.21$ \\
\hline GFAP & $1.24 \pm 0.30$ & $1.31 \pm 0.24$ & $1.11 \pm 0.24$ & $1.10 \pm 0.22$ & $0.87 \pm 0.17$ \\
\hline \multicolumn{6}{|l|}{ DRG } \\
\hline $\mathrm{IL}-1 \beta$ & $1.47 \pm 0.79$ & $0.82 \pm 0.29$ & $0.55 \pm 0.30$ & $0.99 \pm 0.34$ & $1.22 \pm 0.96$ \\
\hline IL-1R1 & $0.97 \pm 0.55$ & $1.13 \pm 0.44$ & $1.32 \pm 0.76$ & $1.15 \pm 0.44$ & $0.59 \pm 0.43$ \\
\hline TNF-a & $2.00 \pm 1.47$ & $0.89 \pm 0.33$ & $0.97 \pm 0.67$ & $2.17 \pm 1.09$ & $0.99 \pm 0.72$ \\
\hline TNFR1 & $1.10 \pm 0.62$ & $1.01 \pm 0.34$ & $0.97 \pm 0.54$ & $1.05 \pm 0.35$ & $0.71 \pm 0.50$ \\
\hline cox2 & $6.69 \pm 6.08^{*}$ & $1.57 \pm 0.92$ & $0.35 \pm 0.32$ & $0.67 \pm 0.40$ & ND \\
\hline GFAP & $1.29 \pm 0.97$ & $0.95 \pm 0.56$ & $1.16 \pm 0.79$ & $1.57 \pm 1.05$ & $0.58 \pm 0.47$ \\
\hline
\end{tabular}

$P$ indicates paw palpation. Significantly altered expression ratios between groups are represented by ${ }^{\star} P<0.05,{ }^{*} P<0.01,{ }^{*} * P<0.001$. DRG: dorsal root ganglia; CFA: complete freund adjuvant; CF: complete freund; PBS: phosphate buffer saline; ND: not determined; IL-1 13: interleukin-1beta; IL-1R1: interleukin-1 receptor type 1; TNF-a: tumor necrosis factor-alpha; TNFR1 and 2: tumor necrosis factor receptor 1 and 2; MCP-1: monocyte chemoattractant protein-1; COX2: cyclooxygenase-2; mPGES: microsomal prostaglandin E synthase; GFAP: glial fibrillary acidic protein; GAPGH: glyceraldehyde 3-phosphate dehydrogenase; NCTC: National Collection of Type Cultures 2472 sarcoma 


\section{DISCUSSION}

The present study shows that chronic pain behaviors during deep tissue damage occur in the absence of spinal neuroinflammation but in the presence of circulating cytokines. In addition, evidence is provided to indicate that the latter may act on DRG cytokine receptors and that mechanical stimulation increases spinal cytokine expression.

Our work extends a number of previous studies showing variable spinal GFAP responses across models of inflammatory and cancer pain. ${ }^{[27-33]}$ It reports the absence of increased spinal cytokine expression in addition to the lack of GFAP up-regulation in models of moderate deep tissue pain. Indeed, the fact that we injected less biologically-active agents and induced less severe pain behavior and tissue damage, compared to previous reports,,$^{[27,29,38]}$ may partly explain discrepancies concerning spinal neuroinflammation between studies.

However, studies employing concentrations and routes of administration of biologically-active agents comparable to those used currently have shown increased spinal GFAP and cytokine expression. ${ }^{[16,30,31]}$ Interestingly, these studies, like those using higher concentrations of disease biologically-active agents, imposed mechanical stimulation or movement on animals. Non-noxious palpation of bone tumor-containing paws increases transcription factor expression in the spinal cord. ${ }^{[32,33]}$ We show here that the palpation induced spinal c-Fos expression, although not to the same extent as CFA-provoked articular inflammation. Since sensory nerve stimulation can induce CNS IL-1 $\beta$ expression, ${ }^{[34,41]}$ we tested the effect of paw palpation on spinal cytokine expression. Our observation that palpation increased spinal IL-1 $\beta$ and IL-1R1 expression in mice with joint inflammation indicates that afferent nerve stimulation during deep tissue injury can indeed induce hallmarks of neuroinflammation. Results obtained in models employing imposed mechanical stimulation to assess pain sensitivity should, therefore, be interpreted with caution.

As we hypothesized that imposed paw stimulation during deep tissue injury influences spinal gene expression, we assessed spontaneous behaviors indicating pain, such as decreased food intake and exploration as well as paw guarding, ${ }^{[36,42]}$ and we studied allodynia only minutes before sacrifice. Although joint inflammation affected exploration more than bone cancer, both conditions reduced food intake and provoked hind paw guarding. The latter behavior is in accordance with earlier studies and has been shown to be reversed by morphine, ${ }^{[38,42]}$ thus suggesting that paw guarding reflects spontaneous pain.
Although experimental joint inflammation and bone cancer gave rise to similar pain behaviors in the absence of spinal neuroinflammation, the underlying mechanisms differ. Subcutaneous CFA injections may result in blood-brain barrier breakdown and increase spinal COX-2 expression, ${ }^{[29,43]}$ that mediates mechanical pain hypersensitivity. ${ }^{[4]}$ Our work confirmed increased spinal COX-2 expression after less severe intra-articular CFA injections suggesting that it also mediates mechanical allodynia during local inflammation. However, in contrast to what has been reported after subcutaneous CFA injection, ${ }^{[27]}$ we did not observe increased spinal cytokine expression in the absence of mechanical stimulation. Interestingly, in addition to IL- $1 \beta$ and TNF- $\alpha$, peripheral IL-6 also increases central COX-2 expression and pain sensitivity during inflammation. ${ }^{[45]}$ Since we observed increased circulating IL-6 concentrations, we propose that IL-6-induced spinal COX-2 upregulation underlies mechanical allodynia after intra-articular CFA injection. Alternatively, circulating IL-6 may have acted on IL-6 receptors in DRG, ${ }^{[23,24]}$ accessible to circulating molecules, ${ }^{[22]}$ to induce COX-2.

In the absence of increased spinal cytokine and COX-2 expression during bone cancer pain behavior, we considered nervous system actions of peripheral cytokines. We confirmed tumor MCP-1/CCL2 production and showed for the first time increased circulating MCP-1/CCL2 and constitutive CCR2 protein expression in murine DRG nociceptors. These findings are important given that circulating molecules can access DRGs and that MCP-1/CCL2 increases nociceptor excitability, ${ }^{[22,46]}$ and suggest that circulating MCP-1/CCL2 action on DRGs contributes to bone cancer pain behavior.

In conclusion, our present work shows that in two different types of deep tissue lesions, inflammatory and neoplastic, signs of spontaneous, chronic pain are not correlated to spinal neuroinflammation, but rather to peripheral cytokines. In addition, we present evidence indicating that mechanical stimulation of the body segment containing the lesion, similar to what may occur during pain sensitivity testing, can induce spinal cytokine expression as a hallmark of neuroinflammation. As such, our work provides important new insights into the occurrence and role of spinal neuroinflammation in chronic pain. Finally, our findings suggest that circulating cytokine action in dorsal root ganglia may contribute to experimental joint inflammation and bone cancer pain.

\section{ACKNOWLEDGMENTS}

We thank Pascale Roux and Alexandra Serre for skilful assistance in PCR and immunohistochemical experiments, 
respectively. This work was supported by a $\mathrm{PhD}$ thesis scholarship to Line Pourtau from la Ligue contre le Cancer and by a Master scholarship to Amarins Nieske Heeringa from KWF Kanker Bestrijding.

\section{REFERENCES}

1. Coleman RE. Skeletal complications of malignancy. Cancer 1997;80:1588-94.

2. Rubens RD. Bone metastases - the clinical problem. Eur J Cancer 1998;34:210-3.

3. Lee DM, Weinblatt ME. Rheumatoid arthritis. Lancet 2001;358:903-11.

4. Creamer P, Lethbridge-Cejku M, Hochberg MC. Where does it hurt? Pain localization in osteoarthritis of the knee. Osteoarthritis Cartilage 1998;6:318-23.

5. van Baar ME, Dekker J, Oostendorp RA, Bijl D, Voorn TB, Lemmens JA, Lemmens JA, Bijlsma JW. The effectiveness of exercise therapy in patients with osteoarthritis of the hip or knee: a randomized clinical trial. J Rheumatol 1998;25:2432-9.

6. Delaney A, Fleetwood-Walker SM, Colvin LA, Fallon M. Translational medicine: cancer pain mechanisms and management. BrJ Anaesth 2008;101:87-94.

7. Ji RR, Xu ZZ, Gao YJ. Emerging targets in neuroinflammation-driven chronic pain. Nat Rev Drug Discov 2014;13:533-48.

8. Ferreira SH, Lorenzetti BB, Bristow AF, Poole S. Interleukin-1 beta as a potent hyperalgesic agent antagonized by a tripeptide analogue. Nature 1988;334:698-700.

9. Watkins LR, Goehler LE, Relton J, Brewer MT, Maier SF. Mechanisms of tumor necrosis factor-alpha (TNF-alpha) hyperalgesia. Brain Res 1995;692:244-50

10. Reeve AJ, Patel S, Fox A, Walker K, Urban L. Intrathecally administered endotoxin or cytokines produce allodynia, hyperalgesia and changes in spinal cord neuronal responses to nociceptive stimuli in the rat. Eur J Pain 2000;4:247-57.

11. Sung CS, Wen ZH, Chang WK, Ho ST, Tsai SK, Chang YC, Wong CS. Intrathecal interleukin-1beta administration induces thermal hyperalgesia by activating inducible nitric oxide synthase expression in the rat spinal cord. Brain Res 2004;1015:145-53.

12. Kwon MS, Shim EJ, Seo YJ, Choi SS, Lee JY, Lee HK, Suh HW. Differential modulatory effects of cholera toxin and pertussis toxin on pain behavior induced by TNF-alpha, interleukin-1beta and interferon-gamma injected intrathecally. Arch Pharm Res 2005;28:582-6.

13. Qin X, Wan Y, Wang X. CCL2 and CXCL1 trigger calcitonin gene-related peptide release by exciting primary nociceptive neurons. J Neurosci Res 2005;82:51-62.

14. Dansereau MA, Gosselin RD, Pohl M, Pommier B, Mechighel P, Mauborgne A, Rostene W, Kitabgi P, Beaudet N, Sarret P, Melik-Parsadaniantz S. Spinal CCL2 pronociceptive action is no longer effective in CCR2 receptor antagonist-treated rats. J Neurochem 2008;106:757-69.

15. Woolf CJ, Allchorne A, Safieh-Garabedian B, Poole S. Cytokines, nerve growth factor and inflammatory hyperalgesia: the contribution of tumour necrosis factor alpha. Br J Pharmacol 1997;121:417-24.

16. Baamonde A, Curto-Reyes V, Juárez L, Meana A, Hidalgo A, Menéndez L. Antihyperalgesic effects induced by the IL-1 receptor antagonist anakinra and increased IL-1beta levels in inflamed and osteosarcoma-bearing mice. Life Sci 2007;81:673-82.

17. Constantin CE, Mair N, Sailer CA, Andratsch M, Xu ZZ, Blumer MJ, Scherbakov N, Davis JB, Bluethmann H, Ji RR, Kress M. Endogenous tumor necrosis factor alpha (TNFalpha) requires TNF receptor type 2 to generate heat hyperalgesia in a mouse cancer model. J Neurosci 2008;28:5072-81.

18. Zhang RX, Li A, Liu B, Wang L, Ren K, Zhang H, Berman BM, Lao L. IL-1ra alleviates inflammatory hyperalgesia through preventing phosphorylation of NMDA receptor NR-1 subunit in rats. Pain 2008;135:232-9.
19. Hu JH, Zheng XY, Yang JP, Wang LN, Ji FH. Involvement of spinal monocyte chemoattractant protein-1 (MCP-1) in cancer-induced bone pain in rats. Neurosci Lett 2012;517:60-3.

20. Pevida M, González-Rodríguez S, Lastra A, Hidalgo A, Menéndez L, Baamonde A. CCL2 released at tumoral level contributes to the hyperalgesia evoked by intratibial inoculation of NCTC 2472 but not B16-F10 cells in mice. Naunyn Schmiedebergs Arch Pharmacol 2012;385:1053-61.

21. Pevida M, González-Rodríguez S, Lastra A, García-Suárez O, Hidalgo A, Menéndez L, Baamonde A. Involvement of spinal chemokine CCL2 in the hyperalgesia evoked by bone cancer in mice: a role for astroglia and microglia. Cell Mol Neurobiol 2014;34:143-56.

22. Abram SE, Yi J, Fuchs A, Hogan QH. Permeability of injured and intact peripheral nerves and dorsal root ganglia. Anesthesiology 2006;105:146-53.

23. Gardiner NJ, Cafferty WB, Slack SE, Thompson SW. Expression of gp130 and leukaemia inhibitory factor receptor subunits in adult rat sensory neurones: regulation by nerve injury. $J$ Neurochem 2002;83:100-9.

24. Andratsch M, Mair N, Constantin CE, Scherbakov N, Benetti C, Quarta S, Vogl C, Sailer CA, Uceyler N, Brockhaus J, Martini R, Sommer C, Zeilhofer HU, Muller W, Kuner R, Davis JB, Rose-John S, Kress M. A key role for gp130 expressed on peripheral sensory nerves in pathological pain. J Neurosci 2009;29:13473-83.

25. Sweitzer SM, Colburn RW, Rutkowski M, DeLeo JA. Acute peripheral inflammation induces moderate glial activation and spinal IL-1beta expression that correlates with pain behavior in the rat. Brain Res 1999;829:209-21.

26. Bao L, Zhu Y, Elhassan AM, Wu Q, Xiao B, Zhu J, Lindgren JU. Adjuvant-induced arthritis: IL-1 beta, IL- 6 and TNF-alpha are up-regulated in the spinal cord. Neuroreport 2001;12:3905-8.

27. Raghavendra V, Tanga FY, DeLeo JA. Complete Freunds adjuvant-induced peripheral inflammation evokes glial activation and proinflammatory cytokine expression in the CNS. Eur JNeurosci 2004;20:467-73.

28. Mao-Ying QL, Wang XW, Yang CJ, Li X, Mi WL, Wu GC, Wang YQ. Robust spinal neuroinflammation mediates mechanical allodynia in Walker 256 induced bone cancer rats. Mol Brain 2012;5:16.

29. Rabchevsky AG, Degos JD, Dreyfus PA. Peripheral injections of Freund's adjuvant in mice provoke leakage of serum proteins through the blood-brain barrier without inducing reactive gliosis. Brain Res 1999;832:84-96.

30. Honore P, Rogers SD, Schwei MJ, Salak-Johnson JL, Luger NM, Sabino MC, Clohisy DR, Mantyh PW. Murine models of inflammatory, neuropathic and cancer pain each generates a unique set of neurochemical changes in the spinal cord and sensory neurons. Neuroscience 2000;98:585-98.

31. Sabino MA, Luger NM, Mach DB, Rogers SD, Schwei MJ, Mantyh PW. Different tumors in bone each give rise to a distinct pattern of skeletal destruction, bone cancer-related pain behaviors and neurochemical changes in the central nervous system. Int $J$ Cancer 2003;104:550-8.

32. Ducourneau VR, Dolique T, Hachem-Delaunay S, Miraucourt LS, Amadio A, Blaszczyk L, Jacquot F, Ly J, Devoize L, Oliet SH, Dallel R, Mothet JP, Nagy F, Fenelon VS, Voisin DL. Cancer pain is not necessarily correlated with spinal overexpression of reactive glia markers. Pain 2014;155:275-91.

33. Schwei MJ, Honore P, Rogers SD, Salak-Johnson JL, Finke MP, Ramnaraine ML, Clohisy DR, Mantyh PW. Neurochemical and cellular reorganization of the spinal cord in a murine model of bone cancer pain. J Neurosci 1999;19:10886-97.

34. Pedersen LM, Jacobsen LM, Mollerup S, Gjerstad J. Spinal cord long-term potentiation (LTP) is associated with increased dorsal horn gene expression of IL-1beta, GDNF and iNOS. Eur $J$ Pain 2010;14:255-60.

35. Gauldie SD, McQueen DS, Clarke CJ, Chessell IP. A robust model of adjuvant-induced chronic unilateral arthritis in two mouse strains. J Neurosci Methods 2004;139:281-91. 
36. Mayer J. Use of behavior analysis to recognize pain in small mammals. Lab Anim (NY) 2007;36:43-8.

37. Palecek J, Paleckova V, Willis WD. The roles of pathways in the spinal cord lateral and dorsal funiculi in signaling nociceptive somatic and visceral stimuli in rats. Pain 2002;96:297-307.

38. El Mouedden M, Meert TF. Evaluation of pain-related behavior, bone destruction and effectiveness of fentanyl, sufentanil, and morphine in a murine model of cancer pain. Pharmacol Biochem Behav 2005;82:109-19.

39. Pourtau L, Leemburg S, Roux P, Leste-Lasserre T, Costaglioli P, Garbay B, Drutel G, Konsman JP. Hormonal, hypothalamic and striatal responses to reduced body weight gain are attenuated in anorectic rats bearing small tumors. Brain Behav Immun 2011;25:777-86.

40. Pfaffl MW, Horgan GW, Dempfle L. Relative expression software tool (REST) for group-wise comparison and statistical analysis of relative expression results in real-time PCR. Nucleic Acids Res 2002;30:e36.

41. Hosoi T, Okuma Y, Nomura Y. Electrical stimulation of afferent vagus nerve induces IL-1beta expression in the brain and activates HPA axis. Am J Physiol Regul Integr Comp Physiol 2000;279:R141-7.

42. Chillingworth NL, Donaldson LF. Characterisation of a Freund's complete adjuvant-induced model of chronic arthritis in mice.
J Neurosci Methods 2003;128:45-52.

43. Beiche F, Brune K, Geisslinger G, Goppelt-Struebe M. Expression of cyclooxygenase isoforms in the rat spinal cord and their regulation during adjuvant-induced arthritis. Inflamm Res 1998;47:482-7.

44. Vardeh D, Wang D, Costigan M, Lazarus M, Saper CB, Woolf CJ, Fitzgerald GA, Samad TA. COX2 in CNS neural cells mediates mechanical inflammatory pain hypersensitivity in mice. J Clin Invest 2009;119:287-94.

45. Oka Y, Ibuki T, Matsumura K, Namba M, Yamazaki Y, Poole S, Tanaka Y, Kobayashi S. Interleukin-6 is a candidate molecule that transmits inflammatory information to the CNS. Neuroscience 2007; $145: 530-8$.

46. Sun JH, Yang B, Donnelly DF, Ma C, LaMotte RH. MCP-1 enhances excitability of nociceptive neurons in chronically compressed dorsal root ganglia. J Neurophysiol 2006;96:2189-99.

Cite this article as: Pourtau L, Heeringa AN, Rovere C, Aubert A, Nahon JL, Miraux S, Konsman JP. Increased circulating rather than spinal cytokines accompany chronic pain behaviors in experimental bone cancer and arthritis. Neuroimmunol Neuroinflammation 2014;1(3):153-60.

Source of Support: Nil. Conflict of Interest: No.

Received: 08-08-2014; Accepted: 15-09-2014 